\title{
THE DONATION OF GAMETES AND THE ANONIMITY OF THE DONORS
}

\author{
R. Krastev and V. Mitev \\ Department of Medical Chemistry and Biochemistry \\ Medical University - Sofia
}

\begin{abstract}
Summary. A study of the public opinion in Bulgaria in regard to the possibility of the adult children, created by gamete donation, to learn who their biological parents are was made. This investigation was an on-line survey. The participants in the study are individuals between 18 and 65 years of age - Internet users. The survey was included into different web sites and this enlarged the number of respondents (up to 994) and 85\% of them were persons in fertile age - from 18 to 43 years. The answers of the respondents in relation of the demographic features - gender, age, education, family status and place of living were studied. The data were calculated with the special statistical product SPSS 16. A critical level of significance 0.05 was used. Results: Almost half (47\%) of the respondents agree that the children born from gamete donors have the right to know at adulthood their biological parents, 35\% disagree and 18\% have no opinion. The demographic features influencing the answers of the question are the gender, the education and the family status of the respondents $(p<0.05)$. Most of the men $(60 \%)$ consider that the children have the right to know their biological parents while only $44 \%$ of the women approve. The highest support of the idea about contact between the donors and their genetic off springs show the people with secondary education (56\%) and the most skeptical are the respondents with high non-medical education (40\%). The family status influences the opinion of the respondents - the approval of the married and unmarried is $38 \%$ and $60 \%$, respectively.
\end{abstract}

Key words: anonymity, gamete donation, assisted reproduction

\section{INTRODUCTION}

T here is no ideal solution of gamete donation from an ethical point of view. There are three groups of participants in this process and their rights can be affected. These are the autonomy and the right of private life of the parents, of the donors and also the right of the child to know its genetic origin [1]. These rights very often can not be satisfied simultaneously.

During the discussion in England [2] before the abolition of anonymity in 2005 the opponents of the abolition underline that this will lead to the decrease in the number of donors and will create discomfort about the couples who must reveal in front of all their infertility. 
According to BBC survey [3] 53\% of all sperm donors in Great Britain are against the changes of the legislation from anonymity to non-anonymity and declare that they will stop to donate. This really happens because after the change in the law in 2005 in the next few years the number of the registered donors decreased from $43 \%$ to $19 \%$ [4].

A law allowing the children after 16 years of age to learn the identity of the donor was passed in Holland in 2004 [5]. During the 15 year lasting discussion about the removal of anonymity, the number of donors and sperm banks decreased with $60 \%$ and $50 \%$, respectively.

Some people consider that it is useless to abolish the anonymity because many parents of children created by gamete donation are not inclined to tell them the truth. For example, a survey among parents of children (4-8 years old) born by donation before the abolition of anonymity in England was made. The data showed that $42 \%$ of the parents do not want to reveal the secret of conception of the children, $17 \%$ have doubts and only $13 \%$ have done this before the 8th year of the child [6].

Why the parents do not tell their children that they have been created with donor's sperm? The parents consider that their sterility concerns only them and must not be shared with the child. Some are afraid from a negative attitude towards their children from the other children. Other parents are afraid that the child may reject the social parent. There are people who want their family to be like the others - this means "normal". When the donor is anonymous this also blocks the parents to tell their children because they will not be able to answer to their questions about the identity of the genetic parent [7].

The proponents of the non-anonymous donation point out that the abolition is necessary because the anonymous donation is contrary to the article 7 of the UN Convention on the rights of the child (1989) - the UNCRC, the CRC - which postulates that the child has the right to know its parents and origin.

The number of sperm donors not always decreases after the removal of the anonymity. Only the profile of the sperm donors in Sweden changed from young students to older men with families [8].

The number of children born from one anonymous donor can not be controlled. In most of the countries up to 20 pregnancies from one donor are allowed but these limits are not always respected. This limit is up to 25 children in Holland but there is a discussion to decrease it due to the risk of blood relations and genetic reasons in case of genetic disease [5]. The limit in England is 10 children, in France and Bulgaria - 5 pregnancies. There are data in the literature that one anonymous donor appeared to be a father of 500 children [9]. The alternative is to have two possibilities - the bank with anonymous and another with no anonymous donors [10]. This practice exists in the USA. The parents have the right to choose but at the second place. The first to choose is the donor and in the situation when most of the donors prefer to remain anonymous, the parents have limited possibilities for selection [11]. This system satisfies the donors and partially the parents but does not consider the right of the children born from anonymous donor and wishing to learn their origin [1].

The donation of sperm in the member states of the European Union is not regulated in five countries. Only anonymous donation is practiced in eleven member states /including Bulgaria/. In another seven states only no anonymous donation is used. There are two member states in which all kinds of donation are banned - Italy and Lithuania. Both types of donation are practiced in three member states.

The egg donation is not regulated in seven member states. Non-anonymous egg donation only is allowed in four countries. Only anonymous egg donation is permitted in eight states. 
Both types of egg donation (anonymous and non-anonymous) is allowed in five member states (including Bulgaria). The egg donation is forbidden in three countries - Italy, Germany and Austria [7].

The purpose of this study was the investigation of the public opinion in Bulgaria in regard to the ethical and legal problems of the assisted reproduction and the fate of the spared embryos.

\section{MATERIALS AND METHODS}

The on-line survey was carried out in cooperation with the company "Kupisait", provider of on-line survey software and corresponding resources. The survey was installed on a specially created for this purpose web-site www.bioetika.org on which a lot of additional information about AR was presented together with a forum for discussion. The web-site had been accessible in Bulgarian language from July 2010 until June 2011.

Cookies were set in order to forestall multiple responses from one person.

Our study is directed towards the Bulgarian people in working capacity age - from 18 to 65 years. Considering the specificity of the questions we preferred to obtain answers from younger persons - from 18 to 43 years of age. That is why www.bioetika.org had been advertised on university web-sites and on www.bg-mamma.com and www.zachatie.org which are visited by people with infertility problems. We supposed that the female respondents will be several times more than the male ones because the web sites www.bg-mamma.com and www. zachatie.org are visited mainly by women.

Eligibility criteria of the respondents: female and male individuals from 18 to 65 years old who have answered to all the questions in the survey.

The survey was containing 25 questions from which 5 are demographical (gender, age, education, marital status, place of residence) and the remaining 20 concerned ethical and legal aspects of AR. The question which is the object of the present paper is "Should the legislation allow the adult children born by gamete donation to learn who are their genetic parents?" The possible answers are three: "yes", "no", "I can not answer".

\section{STATISTICS}

The answers of the questions were encoded and were converted into CSV files for further statistical analysis. The data were treated with statistical package SPSS 16 . The determination of the link between the demographic characteristics and the answers of the respondents was made using the $\chi^{2}$ - method of Pearson Chi-Square in cross tables $2 \times 2$, the Linear by Linear Association in cross tables $2 \times \mathrm{K}$, cross-tabulation, graphical analysis - diagrams of Bar-Chart and one factor dispersion analysis of Kruskal - Wallis. The critical level of significance was 0.05. The zero hypothesis is rejected when $p<0.05$.

\section{RESULTS}

The question of the survey was answered by 937 respondents. The positive answers were $47 \%$ and the negative were $35 \%$.

The demographic characteristics which influenced significantly the answers were the gender, the education and the marital status of the respondents $(p<0.05)$ (Table 1 and Fig. 1, Fig. 2 and Fig. 3). 
Table 1. Demographic characteristics of the respondents

\begin{tabular}{|c|c|c|c|c|c|}
\hline Demographic features & & Yes & No & I can not answer & $P$ value \\
\hline Gender & $\begin{array}{l}\text { men } \\
\text { women }\end{array}$ & $\begin{array}{l}59.4 \\
43.9\end{array}$ & $\begin{array}{l}27.9 \\
36.3\end{array}$ & $\begin{array}{l}12.7 \\
19.8\end{array}$ & 0.0001 \\
\hline Age (years) & $\begin{array}{l}18-35 \\
36-43 \\
44-51 \\
52-65\end{array}$ & $\begin{array}{l}48.0 \\
41.6 \\
48.2 \\
61.9 \\
\end{array}$ & $\begin{array}{l}33.9 \\
37.2 \\
40.3 \\
21.4 \\
\end{array}$ & $\begin{array}{l}18.1 \\
21.2 \\
11.7 \\
16.7 \\
\end{array}$ & 0.504 \\
\hline Education & $\begin{array}{l}\text { Secondary } \\
\text { University } \\
\text { Medical University }\end{array}$ & $\begin{array}{l}56.3 \\
39.9 \\
47.1 \\
\end{array}$ & $\begin{array}{l}29.1 \\
36.9 \\
40.6\end{array}$ & $\begin{array}{l}14.6 \\
23.2 \\
12.3 \\
\end{array}$ & 0.020 \\
\hline Marital status & $\begin{array}{l}\text { Unmarried } \\
\text { Married } \\
\text { Divorced } \\
\text { Widow/widower } \\
\text { Living with partner }\end{array}$ & \begin{tabular}{|l|}
60.4 \\
37.7 \\
53.3 \\
41.7 \\
39.4
\end{tabular} & \begin{tabular}{|l|}
27.5 \\
40.7 \\
21.6 \\
25.0 \\
38.7
\end{tabular} & $\begin{array}{l}12.1 \\
21.6 \\
18.8 \\
33.3 \\
21.9\end{array}$ & 0.0001 \\
\hline Place of Residence & $\begin{array}{l}\text { Capital } \\
\text { Country }\end{array}$ & $\begin{array}{l}47.6 \\
46.7\end{array}$ & $\begin{array}{l}33.3 \\
35.8\end{array}$ & $\begin{array}{l}19.1 \\
17.5\end{array}$ & 0.887 \\
\hline
\end{tabular}

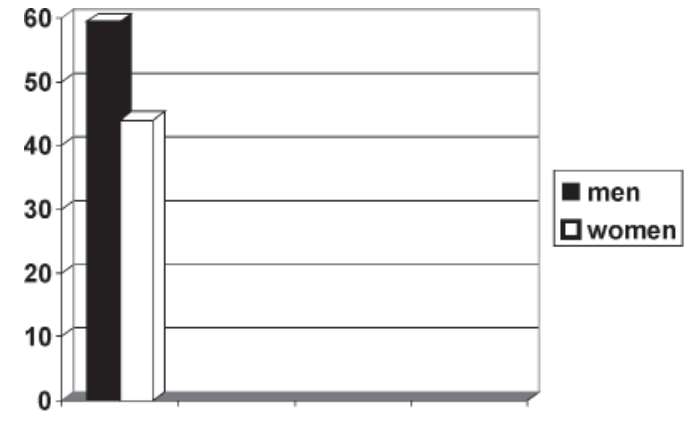

Fig. 1. Acceptance of the right of the child to know its origin depending on the gender of the respondents

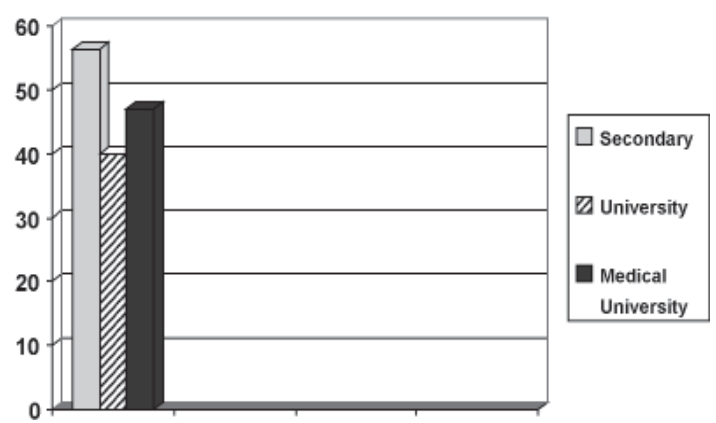

Fig. 2. Acceptance of the right of the child to know its origin depending on the education of the respondents

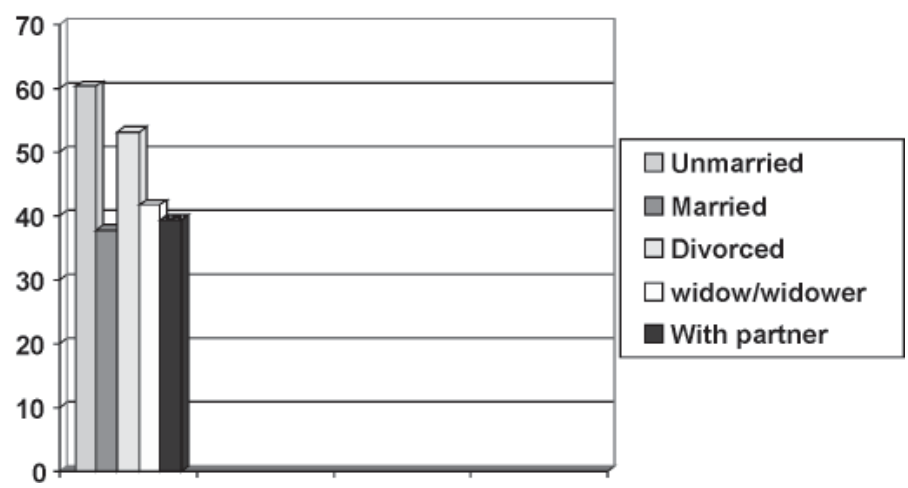

Fig. 3. Acceptance of the right of the child to know its origin depending on the marital status of the respondents 


\section{DISCUSSION}

The question about the use of the gamete donors is linked with the right of the child to know its biological parents as is postulated in the UN Convention on the rights of the child (1989) - the UNCRC, the CRC.

From the total number of respondents to this question $(n=937)$ almost half of them $(47 \%)$ consider that the children born from gamete donation have the right to know at adulthood their biological parents. Almost one third (35\%) have the opposite opinion and $18 \%$ have no opinion.

The demographic characteristics which influence significantly the answers are the gender, the education and the marital status of the respondents $(p<0.05)$ (Table 1 and Fig. 1, Fig. 2 and Fig. 3). Most of the men (60\%) accept that the children born from gamete donation have the right to know at adulthood their biological parents while the acceptance of women is only $44 \%$. The highest support of the idea about contact between the donors and their genetic off springs is demonstrated by the people with secondary education (56\%) and the most skeptical are the respondents with non medical university education (40\%). The marital status seems to have a major influence on the opinion of the respondents with big difference in the approval between unmarried and married, $60 \%$ versus $38 \%$, respectively (Table 1 ). There are also high percent of people without opinion. This is the case of $33 \%$ of the widows and $23 \%$ of the respondents with university education.

There are discussions in many countries about the donor anonymity and the right of the child to identify the donors. The surveys which were made showed that the attitude towards gamete donation varies in the different countries.

The children born from donor insemination in Sweden have the right to obtain information about the identity of the donor by a law from 1984. The non-anonymous egg donation is allowed in 2003 in Sweden and in the survey made in the same year 78\% of women and 71\% of men consider that the child must be told that it is born from gamete donation. But only $48 \%$ of the women and $48 \%$ of the men accept the discovering of the donor identity to the child [12]. These data are near to our average percent of acceptance (47\%) but the difference with our results is that here there is no statistically significant difference in the answers of the women and the men.

The same authors realized a survey only among women $(n=729)$. A significant part of these women $(n=118)$ were ready to become egg donors but only $38 \%$ of the potential egg donors would be glad to meet their biological child later [13].

A later survey in Sweden between couples using donation in the period 2005-2008 shows an increase in the percentage of acceptance [14]. In regard to the sperm donation $53 \%$ of the men and $52 \%$ of the women accept the child to dispose with identifying information about the donor. The percentage of acceptance is even higher about egg donation $-55 \%$ of the men and $67 \%$ of the women. This statistically significant difference is contrary to our results in which the men are more favorable (60\%) in comparison to the women (44\%).

The donor anonymity is preferred in Japan. A survey with 3647 respondents shows that $67 \%$ of the men and $62 \%$ of the women support the anonymous sperm donation. The anonymous egg donation has also a majority of proponents $-71 \%$ of the men and $63 \%$ of the women [15].

During the discussion about the revision of the Law on Bioethics in France from 2009 to 2011 several surveys are realized about abolition of the anonymity of gamete donation. The survey of the sociological agency IPSOS in December 2009 [16] shows that $77 \%$ of the respondents are proponents of the anonymous donation and are opponents to its abolition. Similar data are obtained in 2011 in the on-line survey of the medical site "Doctissimo" [17]. Only $30 \%$ of the respondents are supporting the abolition of the anonymity and $65 \%$ are on the opposite opinion. 
The medical workers in Denmark want to keep the anonymous donation and $82 \%$ of the men and $90 \%$ of the women consider that the anonymity is good for the participants in the procedure [18]. A survey made in Greece shows that the older generation supports the anonymous donation while the younger disagree with it [19].

The anonymous donation was forbidden in Great Britain in 2005 but the survey made there in 2006 shows that $58 \%$ of the respondents prefer the anonymous donation [20].

The identification of the donors has the highest number of supporters in Holland where since 2004 full information of the donors is given to the children over 16 years of age. The survey between heterosexual couples with fertile problems and lesbian couples shows that $63 \%$ of the hetero couples and $98 \%$ of the lesbians will choose non-anonymous donor [21]. In our country the people with secondary education are more inclined the donors to be nonanonymous in comparison with those with university education.

The parents in the USA have the possibility to choose between anonymous and nonanonymous donor. The on-line survey made on the site of the so called "donor twins" (children created from one and the same donor) concerned the mothers and the fathers using donors gametes. $67 \%$ of them have chosen anonymous donor. $42 \%$ underline that the main reason for their choice was the absence of non-anonymous gametes in the AR clinic at the moment of the fertilization [11].

The above mentioned data point out that the maintenance of donor's anonymity is preferred in the countries where it exists. The attitude towards identification of the donors in countries where the donation is non-anonymous is changing and the number of people considering that the children have the right to know their origin increases.

\section{CONCLUSIONS}

The present study shows that the public opinion in our country is more inclined to accept the abolition of the anonymous donation. The highest number of supporters of donors' identification is in the group of unmarried men with secondary and medical university education. The maintenance of the anonymity is supported mainly by the married women with university education. These conclusions could not be categorical because the study is not representative for the whole country.

\section{REFERENCES}

1. ESHRE Task Force on Ethics and Law III Gamete and embryo donation - Human Reproduction, 2002; 17(5): 1407-1408.

2. McWhinnie A. Gamete donation and anonymity, Hum Reprod, 2001; 16(5): 807-817.

3. Hill M (2002) Sperm donors "want to keep anonymity". BBC News. Available from http://news.bbc.co.uk/1/hi/ health/2329675.stm

4. Brett S, Sacranie RR, Thomas GE, and Rajkhowa R. Can we improve recruitment of oocyte donors with loss of donor anonymity? A hospital-based survey. Hum Fertil (Camb) 2008; 11: 101-107.

5. Janssens P. M. W, Simons A. H. M, van Kooij R. J, Blokzijl E, and Dunselman G. A. J. A new Dutch Law regulating provision of identifying information of donors to offspring: background, content and impact. Hum. Reprod, 2006; 21(4): 852-856.

6. Lycett E, Daniels K, Curson R, and Golombok S. School-aged children of donor insemination: a study of parents' disclosure patterns. Hum. Reprod., 2005; 20(3): 810-819.

7. Krastev R, Mitev V. Law and bioethics of the assisted reproduction in the European Union, Sofia, ed. Iztok-Zapad, 2014, p.29.

8. Daniels K, and Lalos O. The Swedish Insemination Act and the availability of donors. Hum. Reprod, 1995; 12 : 1871-1874. 
9. Fichou K. (AFP) $($ Oct 8, 2011) Sperm donors father huge "families" in US, Canada Available at www.google. com/.../afp/.../ALeqM5jT8W3P_gpVoAZi1l6ShG5zH1...

10. Pennings, G., The "double track" policy for donor anonymity. Hum. Reprod., 1997; 12; 2839-2844.

11. Frith, L, Blyth, E., Farrand, A., UK gamete donors' reflections on the removal of anonymity: implications for recruitement. Hum. Reprod, 2007; 22(6): 1675-1680.

12. Skoog Svanberg, A., Lampic, C., Bergh, T., Lundkvist, Ö. Public opinion regarding oocyte donation in Sweden. Human Reproduction 2003a; 18(5): 1107-1114.

13. Skoog Svanberg, A., Lampic, C., Bergh, T., Lundkvist, Ö. Characterization of potential oocyte donors in Sweden. Human Reproduction 2003b; 18(10):2210-2215.

14. Isaksson, S., Skoog Svanberg, A., Sydsjö, G., Thurin-Kjellberg, A., Karlström, P. O., Solensten, N.-G., Lampic, C. Two decades after legislation on identifiable donors in Sweden: are recipient couples ready to be open about using gamete donation? Human Reproduction 2011; 26(.4): 853-860.

15. Minai, J., Suzuki, K., Takeda, Y., Hoshi, K., Yamagata, Z. There are gender differences in attitudes towards surrogacy when information on this technique is provided. European Journal of Obstetrics \& Gynecology and Reproductive Biology 2007; 132: 193-199.

16. http://www.ipsos.com/interviews

17. http://www.doctissimo.fr/html/dossiers/genetique/14922-enquete-la-bioethique-et-vous

18. De la Fuente Fonnest I., Finn Søndergaard, Gert Fonnest and Agnette Vedsted-Jacobsen, Attitudes among health care professionals on the ethics of assisted reproductive technologies and legal abortion. Acta Obstet Gynecol Scand, 2000; 79: 49-53.

19. Papaharitou S, Nakopoulou E., Moraitou M., Hatzimouratidis K. and Hatzichristou D. Reproductive health and midwives: Does occupational status differentiate their attitudes on assisted reproduction technologies from those of the general population? Human Reproduction 2007; 22(7): 2033-2039.

20. YouGov Assisted Reproduction Survey On behalf of Progress Educational Trust Summ ary report, www. YouGov. com novembre 2006.

21. Brewaeys, A., De Bruyn, J. K., Louwe, L. A., Helmerhorst, F. M. Anonymous or identity-registered sperm donors? A study of Dutch recipients' choices. Hum. Reprod, 2005; 20(3): 820-824.

\section{Corresponding author:}

Radoy Krastev

Department of Medical Chemistry and Biochemistry

Medical University

1431 Sofia, Bulgaria

1, Sv. G. Sofiyski st.

e-mail: rsvetk@gmail.com 